\title{
Erratum to: The Efficacy of Cognitive Behavioral Therapy: A Review of Meta-analyses
}

Stefan G. Hofmann • Anu Asnaani •

Imke J. J. Vonk • Alice T. Sawyer •

Angela Fang

Published online: 8 January 2014

(C) Springer Science+Business Media New York 2014

Erratum to: Cogn Ther Res (2012) 36:427-440

DOI 10.1007/s10608-012-9476-1

Unfortunately, on p. 435, column 1, first line of the Table 1 has been published incorrectly as "Borderline Personality Disorder" in the original publication.

It should be replaced with "Body Dysmorphic Disorder."

The online version of the original article can be found under doi:10.1007/s10608-012-9476-1.

S. G. Hofmann ( $₫)$ · A. Asnaani · I. J. J. Vonk ·

A. T. Sawyer - A. Fang

Department of Psychology, Boston University, 648 Beacon St.,

6th floor, Boston, MA 02215, USA

e-mail: shofmann@bu.edu 